\title{
Factors Affecting Student Engagement: A Case Study Examining Two Cohorts of Students Attending a Post-1992 University in the United Kingdom
}

\author{
Mark Groves $^{1}$, Christopher Sellars ${ }^{1}$, Julian Smith ${ }^{1} \&$ Alison Barber ${ }^{1}$ \\ ${ }^{1}$ Institute of Sport, Faculty of Education Health \& Wellbeing, University of Wolverhampton, Walsall, United \\ Kingdom \\ ${ }^{1}$ Correspondence: Julian Smith, Deputy Director of the Institute of Sport, Faculty of Education Health \& Wellbeing, \\ University of Wolverhampton, Gorway Road, Walsall, WS1 3BD, United Kingdom. Tel: 44-1-902-323-260. E-mail: \\ julian.smith@wlv.ac.uk
}

Received: November 7, 2014

Accepted: December 20, 2014

Online Published: January 8, 2015

doi:10.5430/ijhe.v4n2p27

URL: http://dx.doi.org/10.5430/ijhe.v4n2p27

\begin{abstract}
Issues relating to student retention and student engagement remain high on the agendas of higher education institutions worldwide. This case study considers the factors that impact on student engagement within a sample of first year undergraduate sports students attending a post 1992 university in the West Midlands region of the United Kingdom. These participants had started their three-year degree courses at the beginning of either the 2011/12 or the 2012/13 academic years. It should be noted that this meant that data collection straddled the introduction of higher student fees for students attending English universities. Data for the study were collected using a quantitative questionnaire and follow up focus groups. Although a number of different factors were found to encourage student engagement the quality of student relationships with their teachers was found to be the most important. Although it was beyond the scope of this study to draw definite conclusions about the impact of higher student fees in this area our data did suggest the possibility that these higher fees might result in staff-student relationships becoming even more important in encouraging student engagement. It is recommended that future research examines the impact of student fees in this area in more detail.
\end{abstract}

Keywords: Student engagement, Student fees, Staff-Student relationships

\section{Introduction}

Issues relating to student retention and student engagement remain high on the agendas for higher education (HE) institutions worldwide (Busse, 2013; Zepke, Leach, \& Butler, 2010). According to Zepke and Leach (2010) the way in which students engage with their studies and what they, their institutions, and their educators can do to improve this engagement has been a well-researched area since the 1990's. To make sense of the complexity of this research Zepke et al. (2010) completed a review of the international engagement literature and found that this literature has used a number of lenses to investigate influences on engagement. This review resulted in the development of a Conceptual Organiser with two distinct features. The first identifies the key lenses employed within the engagement literature and the second suggests indicators of outcomes that might be achieved by using each lens. This Conceptual Organiser is presented in figure one. 


\begin{tabular}{|c|c|}
\hline Lenses on engagement & Chosen indicators \\
\hline $\begin{array}{l}\text { Motivation and agency (Engaged students are } \\
\text { intrinsically motivated and want to exercise their } \\
\text { agency) }\end{array}$ & $\begin{array}{l}\text { A student feels able to work autonomously } \\
\text { A student feels they have relationships with others } \\
\text { A student feels competent to achieve success }\end{array}$ \\
\hline $\begin{array}{l}\text { Transactional engagement (Students engage with } \\
\text { teachers) }\end{array}$ & $\begin{array}{l}\text { Students experience academic challenge } \\
\text { Learning is active and collaborative inside and outside } \\
\text { the classroom } \\
\text { Students and teachers interact constructively } \\
\text { Students have enriching educational experiences }\end{array}$ \\
\hline $\begin{array}{l}\text { Transactional engagement (Students engage with } \\
\text { each other) }\end{array}$ & $\begin{array}{l}\text { Learning is active and collaborative inside and outside } \\
\text { the classroom } \\
\text { Students have positive, constructive peer relationships } \\
\text { Students use social skills to engage with others }\end{array}$ \\
\hline $\begin{array}{l}\text { Institutional support (Institutions provide an } \\
\text { environment conducive to learning) }\end{array}$ & $\begin{array}{l}\text { There is a strong focus on student success } \\
\text { There are high expectations of students } \\
\text { There is investment in a variety of support services } \\
\text { Diversity is valued } \\
\text { Institutions continuously improve }\end{array}$ \\
\hline $\begin{array}{l}\text { Active citizenship (Students and institutions work } \\
\text { together to enable challenges to social beliefs and } \\
\text { practices) }\end{array}$ & $\begin{array}{l}\text { Students are able to make legitimate knowledge claims } \\
\text { Students can engage effectively with others including } \\
\text { the "other" } \\
\text { Students are able to live successfully in the world } \\
\text { Students have a firm sense of themselves Learning is } \\
\text { participatory, dialogic, active and critical }\end{array}$ \\
\hline $\begin{array}{l}\text { Non-institutional support (Students are supported by } \\
\text { family and friends to engage in learning) }\end{array}$ & $\begin{array}{l}\text { Students' family and friends understand the demands of } \\
\text { study } \\
\text { Students' family and friends assist with e.g. childcare, } \\
\text { time management } \\
\text { Students' family and friends create space for study } \\
\text { commitments }\end{array}$ \\
\hline
\end{tabular}

Figure 1. Zepke, Leach and Butler's (2010) Conceptual Organiser

Zepke et al. (2010) also completed some research using New Zealand-based students in an attempt to establish which individual factor might have the greatest impact on student engagement and were able to identify that student engagement with their teachers had the greatest influence in this area. The aim of the current case study is to explore the relevance of this conceptual organiser within a UK context and to examine which of the lenses within it might be considered the most important in terms of student engagement within the UK. Within the paper we will firstly consider the literature that has examined student engagement using Zepke et al. (2010) Conceptual Organiser as a starting point. 
Following this section the data collection and analysis techniques utilised are outlined in the methodology section. A discussion of the findings to emerge from our study is followed by a concluding section.

\subsection{Factors influencing student engagement}

The following section considers the literature that has examined student engagement within the framework of Zepke et al. (2010) Conceptual Organiser.

\subsubsection{Student motivation}

Zepke and Leach (2010) explained that motivation is not a unitary concept. Moreover, Deci and Ryan $(1985,2002)$ in their Self-determination Theory (SDT) of motivation make the distinction between intrinsic motivation (referring to doing something because it is inherently enjoyable and interesting), and extrinsic motivation (referring to doing something because it leads to a separate end outcome, and which in turn is broken down into four increasingly less autonomous forms of motivation: integrated regulation, identified regulation, introjected regulation and externally regulated ). Intrinsic motivation is likely to assist self-determination (the degree to which an individual's behavior is self-motivated and self-determined), while only certain forms of extrinsic motivation will do the same. Indeed, Zepke et al. (2010) Conceptual Organiser suggests that the most engaged students will be intrinsically motivated. SDT has been well supported by large-scale empirical studies and it has been suggested that it is well suited to explaining the motivation surrounding student engagement (Busse, 2013; Wang \& Eccles, 2013; Zepke \& Leach, 2010). Moreover, and drawing further on SDT, it suggests students are more likely to be intrinsically motivated if they can develop a sense of belonging within their institution (Russell \& Slater, 2011; Zepke \& Leach, 2010); if feelings of autonomy can be encouraged (Russell \& Slater, 2011; Zepke \& Leach, 2010); and if they can develop a sense of competence within their studies (Llorens, Schaufeli, Bakker, \& Salanova, 2007; Regaldo, 2003; Russell \& Slater, 2011; Yorke \& Knight, 2004; Xuereb, 2013; Zepke \& Leach, 2010). The need for students to develop a sense of competence seems to be particularly important, with Fazey and Fazey (2001) suggesting that institutions should give their students the opportunity to increase perception of their competence at the earliest possible opportunity.

In today's HE environment there are other factors that might also affect student intrinsic motivation. For example, students may have started to feel that their choice in terms of coming to university is diminished due to parental and societal expectation, and current employment opportunities. In other words, it is no longer an intrinsic choice, but a path that they are expected to follow (Case, 2007, 2008; Fazey \& Fazey, 2001; Mann, 2001). Moreover, it is suggested that degree courses that increasingly focus on potential career pathways may encourage students to focus on the end product rather than the actual process of learning itself (Aldcroft, 2011; Byrne \& Flood, 2007).

\subsubsection{Transactional engagement (student - teacher interactions)}

There is a strong pattern in the literature, which suggests that student-teacher interactions are a crucial factor in encouraging student engagement. To encourage student engagement teachers ${ }^{1}$ need to be enthusiastic (Bryson \& Hand, 2007; Krause \& Coates, 2008; Russell \& Slater, 2011) and well prepared (Mearns et al. 2007 cited in Zepke \& Leach, 2010; Russell \& Slater, 2011), but perhaps more importantly it is crucial that teachers are seen to be approachable (Russell \& Slater, 2011), willing to engage with students in class and on a one to one basis (Case, 2007), and that they are perceived to have a genuine interest in students, making themselves freely available to discuss student progression (Bryson \& Hand, 2007; Krause \& Coates, 2008). Umbach and Wawrzynski (2005) argued that teacher-student interactions are perhaps the most important factor in encouraging student learning and seemed to challenge teachers and institutions to place a higher value on this particular role.

Zepke et al. (2010) Conceptual Organiser further suggests that one potential outcome of positive staff-student interaction is that students will experience academic challenge. Zepke and Leach (2010) argued that enriching experience and academic challenge are likely to engage students and suggested that teachers should challenge their

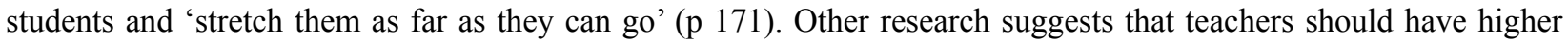
expectations of their students (Krause \& Coates, 2008; Umbach \& Wawrzynski, 2005). Indeed, Coates (2008) outlined that students involved in higher forms of learning such as analysis, synthesis and evaluation tend to be more engaged.

\subsubsection{Transactional engagement (student - student interactions)}

Peer relationships also appear to be important in encouraging student engagement with their studies (Krause \& Coates, 2008; Moran \& Gonyea, 2003; Umbach \& Wawrzynski, 2005), but the development of these relationships should not be left to chance; indeed, teachers can be pivotal in allowing such relationships to develop. For example, Krause (2005 cited in Zepke \& Leach, 2010) argued that asking students to work together in learning communities can enhance a sense of student belonging, while Zepke and Leach (2010) also argued that active and collaborative learning has benefits for engagement that warrant investment by teachers and institutions alike. Moreover, Case (2007) found that 
when teachers make a specific effort to develop student peer relationships, students are more likely to break out of a cycle of alienation and disengagement with their course.

\subsubsection{Institutional support}

The engagement literature also considers what institutions can do to engage their students. The culture of the institution (Leach \& Zepke, 2011) and the first year experience provided by the institution (Reason, Terenzini, \& Domingo, 2006) would both appear to be crucial factors in encouraging student engagement. Institutions should also provide a range of support services for students. This might include high quality libraries and learning systems (Russell \& Slater, 2011); mentoring schemes and essay planning sessions (Leach \& Zepke, 2011); and the provision of adequate childcare (Lewis \& Middleton, 2003 cited in Zepke and Leach, 2010). Equally important is the need for institutions to adapt to changing student expectations. In the ever changing landscape of HE, Krause (2005 cited in Zepke and Leach, 2010) outlined that an increasing proportion of students find themselves in paid employment, with many outlining the impact that this has on their studies. Zepke and Leach (2010) argued that such students expect their studies to fit in with their lives rather than the other way around. Institutions must understand the challenges posed by such students and adapt to them.

\subsubsection{Active citizenship}

There is a small body of research that considers the concept of active citizenship and how this might relate to student engagement. Leach and Zepke (2011) explained that the concept of active citizenship emerged from critiques of the way that engagement is generally considered within the literature; that is, as something that is focussed on academic achievement, but that leads to learning lacking in social context. Zepke, et al. (2010) argued that students and institutions might work together to enable students to challenge social beliefs and practices, to make legitimate knowledge claims, to engage effectively with a diverse range of 'others', to live successfully in the world and to have a firm sense of themselves, and that such students might be described as active citizens and be more likely to engage.

\subsubsection{Non institutional support}

The final area that is likely to impact on student engagement is concerned with the area of non-institutional support, with many students facing 'major challenges outside the classroom' (Leach \& Zepke, 2011, p199). These challenges include responsibility to family, work and social networks as well as money issues, time poverty and feelings of fatigue. Zepke et al. (2010) suggested that students might be more likely to engage if their family and friends understand the demands of study; assist with child care and time management; and create space for study commitments.

With the above in mind Zepke et al. (2010) Conceptual Organiser would seem to provide a worthwhile framework with which to study student engagement. The aim of this case study is also to consider the extent to which this framework is relevant within the UK, and to consider which of the lenses outlined above might be the most important within a UK context. We will also explore the extent to which students report changes in the factors that influence their motivation to engage pre- and post-higher tuition fees, drawing on the motivation theoretical framework provided by Deci and Ryan (2000) and the conceptual framework of Zepke et al.

\section{Methods}

\subsection{Participants}

Participants were students enrolled on one of five degree courses within the Sport \& Physical Activity Department at a post-1992 university in the West Midlands region of the UK. Data were collected from two different cohorts over the two year duration of the study. Participants in the first data collection were first year students $(n=165)$ who started their degree course at the start of the 2011/12 academic year. Participants in the second data collection were first year students ( $n=133$ ) who started their degree course at the start of the 2012/13 academic year. All participants gave informed consent, and institutional ethical approval was granted.

It should be noted that these two cohorts straddled the introduction of higher student fees in England at the start of the 2012/13 academic year. These higher fees meant that students attending English universities could incur a debt of up to $£ 27,000$ for a three year degree course. Allen (2012) suggested that this could have implications in terms of students' expectations of (and engagement in) their university experience and so the change in fee structure should be acknowledged as a potential factor in the findings of this case study.

\subsection{Design and procedure}

This study used a mixed method approach. Quantitative data were collected using an adapted version of The Student Engagement Questionnaire used in a series of studies that were part of a project funded by the Teaching and Learning Research Initiative in New Zealand (Russell \& Slater, 2011; Zepke et al. 2010; Zepke, Butler, \& Leach, 2012; Zepke, 
Leach, \& Butler, 2011). The questionnaire - adapted to include changes in terminology more suitable to a UK context included a series of 5 point likert-type questions that were related to the lenses of engagement identified by Zepke, et al. (2010). All participants completed the questionnaire using Surveyor, an online survey package. On completion, students were asked if they would be willing to participate in a follow up qualitative focus group.

Students who expressed an interest in participating in a focus group were contacted and a total of four focus groups, two in each phase of the study, were conducted Each focus group included between 3 and 5 participants and lasted between 60 and 90 minutes. The two first named authors led the focus groups, and in an attempt to address a potential power imbalance we ensured that they led focus groups which included students that they would not normally teach. In addition, we were confident that our choice of focus group interview over individual interview would help to redress any potential power imbalance as group interviews allow participants to better overcome issues of nervousness or reticence, and to have a greater degree of control in the direction and content of the research (Roberts 2011). Moreover, we made the focus groups as informal as possible encouraging participants to speak freely and honestly about the issues central to the study (Clarke \& Lane, 2005). Finally, we emphasised that student participation was entirely voluntary, with the process of gaining informed consent making it clear that they could withdraw at any time.

\subsection{Data analysis}

Summary and descriptive statistics were obtained directly from the Surveyor survey reports. These included the number and percentage of participants who indicated each option on the Likert scale for each question. Quantitative data were also analysed using SPSS (v16.0; SPSS, inc., Chicago, IL, USA). The differences in the responses across cohorts were examined using the Mann Whitney-U test as the responses to questions (the dependent variables) were given on ordinal likert scales, and there were two categorical independent groups. Significance was set at the $P<0.05$ level.

Focus group interviews were recorded using a digital dictaphone and transcribed verbatim. In order to identify the predominant themes running through these interview transcripts they were coded using N:Vivo 8 computer software for qualitative data analysis. Thematic analysis was undertaken; this involved the reading of the transcripts and the grouping together of data considered to be conceptually similar in nature (Silverman, 2006; Strauss \& Corbin, 1998). Initial reading of the transcripts identified potential coding categories, while a number of subsequent readings allowed for a more systematic coding in which extracts from the interviews were formally allocated to the codes identified during the initial read through (Patton, 2002). This process was undertaken independently by the two first named authors who then met to discuss the themes that had emerged from this analysis. The themes discussed here are those identified following discussions between these two authors. By the end of this process three robust themes emerged from the data. We have called these themes 'Can I do it?', 'It's great when they say hello!' and 'The lectures have got to add something!'. These themes form the basis of the discussion that follows.

\subsubsection{Theme one - Can I do it?}

Literature examining the concept of student engagement has revealed that student motivation to engage can be enhanced by feelings of competence (Llorens et al., 2007; Russell \& Slater, 201; Yorke \& Knight, 2004; Zepke \& Leach, 2010) - experience oneself as effective in one's interactions with the social environment (Elliot \& Dweck, 2005) - and a sense of belonging (Zepke \& Leach, 2010; Russell \& Slater, 2011). Responses to a number of the questions in our questionnaire seemed to reflect this idea. For example, many of our participants in both the first $(94 \%)$ and second (88\%) cohorts revealed that feeling they belonged at university was either important or very important to them. Similarly, $99 \%$ and $97 \%$ of students in the first and second cohorts respectively rated 'knowing how to achieve their goals' as either important or very important.

Our interpretation of our qualitative data also suggested that feelings of competence were crucial and that these feelings could encourage engagement; this is consistent with numerous other research findings in this field, such as Wang and Ellis (2013). The extracts below, and several others like them, revealed how indicators of success, such as grades achieved in early assignments, helped to improve student perceptions of their own academic competence. In particular we were very interested in how many of the students used phrases such as 'I can do it' in order to explain subsequent improved engagement with their studies. As Regaldo (2003) and Xuereb (2013) have explained, students who are successful gain confidence in themselves and are more likely to engage. The following data reflects this idea:

I just thought it was going to be easy. I was just like 'Oh bed, so warm.' (everyone laughs) 'I'll just stay there'. But erm, obviously like you're doing your exams and it's not as easy as you think and I got alright grades so I was like 'I can do it'. So I got my finger out of my arse a bit and started coming (Female Student, Cohort One) 
Yeah, I was struggling with like one of the lectures and I was just like 'I'm going to fail it, I'm just going to end up re-sitting it'. But when I got the grade for the first exam I was actually quite surprised at what I got. That obviously motivated me more because obviously I can get good grades so I'll just put more effort in this semester (Female Student, Cohort One).

It kind of increases your confidence knowing that, if you come out of the first year with straight A's and a few B's you are going to feel more confident in yourself that I can do this. Whereas if you come out in D's and you are doing an assignment in the second year you are going to think this is tough (Female Student, Cohort Two).

I think that once you start getting through the first year knowing that you can work to deadlines, you can go and read on your own, you can get the grades, then that motivates you even more for next year knowing that you can do it (Female Student, Cohort Two).

Our interpretation of the data in this section clearly relates to the motivation lens within Zepke et al. (2010) Conceptual Organiser and suggests that within our sample issues related to intrinsic motivation were important in encouraging student engagement. Specifically these data agree with Zepke, et al. (2010) chosen indicators by revealing that feelings of academic competence were particularly important. With this in mind we would support the proposal of Fazey and Fazey (2001), and Busse (2013) that degree students should be given the opportunity to increase their perceived competence in academic tasks at the earliest possible opportunity.

2.3.2 Theme two - it's great when they say hello!

Within SDT, relatedness is seen as one of the three key need components. It refers to the need to experience oneself as connected to other people (Connell \& Wellborn, 1991). Relatedness need fulfilment will occur when teachers and peers create a supportive environment. A key theme emerging from our data was that relationships were very important in encouraging student engagement. In particular, our data included a robust theme in terms of the importance that our participants attached to their relationships with staff.

It's more encouraging, I think, yeah, it's more encouraging. Like the more they like... stop you outside or whatever and say hello and all that. It's more encouraging for you to go to the lectures (Female Student, Cohort One).

I think if you have the same lecturer all the time, obviously if you get on with their learning and you like them as a lecturer then I think you want to have them continuously every week. Like we've been having like one lecturer for like Physiology and Biomechanics and we have him for practicals and he'll come and teach in the lecture as well like straight after... You build a rapport with them and I think with Bill I think everybody has that because he knows us now (Female Student, Cohort One).

On our first day on our first lecture a lecturer came up to me and just thanked me for answering a question in the first lecture. It was only just a one or two word answer or something like that, but he just came up and said thank you for the answer and thank you for stepping forward and that for me was a big thing because obviously I had been out of education for a while and to have that on your first day made you feel part of the group and helps you settle in (Male Student, Cohort Two).

I felt really appreciated in my first week, the welcome week when we did a few activities in the sports hall because my personal tutor came up to me and got to know me a bit more, about my athletics and my sport and they introduced me to one of the sports leaders or coaches so that I could kind of compete for the uni, but it is how he approached me because he had heard that I was in athletics so it made me feel more appreciated that someone was actually looking into what I did and was taking notice of what I did (Female Student, Cohort Two).

Considering the amount of literature outlining the importance of staff-student relationships in helping students to engage with their studies, such findings may not be surprising. Indeed, Wang and Eccles (2013) state that school engagement is optimised when students perceive that the school environment fulfils their needs for competence, autonomy, and relatedness, the components contributing to self-determined motivation. Our data clearly reveals the importance of the transactional engagement (student-teacher interactions) element of Zepke et al. (2010) Conceptual Organiser. It also supports previous research that suggests that staff can help students to engage by being approachable (Russell \& Slater, 2011); willing to engage with students in class and on a one to one basis (Case 2007); and by having a genuine interest in student's progress (Bryson \& Hand, 2007; Krause \& Coates, 2008). As noted by Zepke, Leach \& Butler, (2010) it may also be that teachers are motivational agents in their own right, providing the conditions that can aid intrinsic motivation, but also by providing a source of the extrinsic motivation that is not as well recognised by Self-Determination Theory. So, whilst Wang and Eccles (2013) consider the value of teacher emotional support as a 
factor contributing to behavioural engagement at school, it appears also to be the case in higher education.

At this point, we should highlight that while the staff-student relationships were seen as important throughout our data the students in our second cohort seemed to have increased expectations in terms of what they would expect from these relationships. So, while students in cohort one commented on what they expected in terms of staff availability, the theme appeared to be much more robust within the data collected from the second cohort of participants. Some of the students within this cohort actually cited the increase in student fees as a reason for these increased expectations:

So if you have physiology every Thursday so if I didn't get something and I sent an email off on the Friday, I would probably expect something back by the Sunday, and if I haven't got something back by the Sunday and I am still not understanding what is going on I will probably send another one, either to the same person or to the Head of Physiology or something who perhaps didn't take the lecture, but could point me in the right direction (Male Student, Cohort Two).

I just expect more like...there is only so much research and independent reading that we can do on a given subject, we can do all that but if we still don't understand it the go to person is the person who teaches it to us and if they don't want to reply to our emails or get emails off us asking them for help sometimes I just think, well why the hell are you here, why are you teaching (Female Student, Cohort Two).

Yeah, but I think it is more so as well with the fees. You just expect there to be a little more helping (Female Student, Cohort Two).

And I did expect more from the lectures and more from our lecturers for the fact that we are paying more than the previous years (Female Student, Cohort Two).

We would acknowledge that such a difference between the two cohorts was not as evident in the quantitative data collected around the importance of staff-student relationships. Nevertheless, the presence of such a theme in the second phase of qualitative data collection certainly raises the possibility that higher student fees may have increased expectations in terms of what students might expect from their interactions with staff.

With the above in mind, we might argue that the increased focus on staff-student interaction in our second cohort of students might account for the reduced importance that these students seemed to attach to the development of relationships with their peers. While these relationships have been found to be important in encouraging student engagement (Krause \& Coates, 2008; Moran \& Goneya, 2003; Umbach \& Wawrzynski, 2005) the students in our second cohort seemed less concerned. Indeed, data analysis revealed that this was the only area where there were significant differences in the quantitative data across the two years of our study, with the students in the second cohort attaching significantly less importance to the development of peer relationships. For example, Mann Whitney U-tests revealed that participants in the second cohort attached significantly less importance to 'making social contacts with other students' $(U=9621, \mathrm{p}=0.037)$; 'feeling accepted by other students' $(U=9529, \mathrm{p}=0.026)$; 'wanting to learn alongside other students' $(U=9351, \mathrm{p}=0.01)$; and 'attending social events run by their institution' $(U=8848, \mathrm{p}=$ 0.003). In addition, students in the second cohort were significantly more likely to agree or strongly agree that 'social activities interfere with their study' $(U=9044, \mathrm{p}=0.004)$.

The data emerging in this theme suggests that student engagement with teachers is a crucial element in encouraging student engagement. Moreover, there is a suggestion within our data that this factor may have become even more important since the rise in student fees. While, it is beyond the scope of this case study to suggest that an increase in student fees might have a direct impact on the nature of student engagement, our findings certainly raise an interesting possibility. One of the lenses of engagement in Zepke et al. (2010) Conceptual Organiser was institutional support, with Zepke and Leach (2010) arguing that this should include the ability of institutions to adapt to changing student expectations. The data collected in the current case study suggests that institutions may face a challenge in terms of how they can help staff to meet these changing expectations.

\subsubsection{Theme Three - The lectures have to add something!}

The final theme to emerge from our data again links to the transactional engagement (Student-teacher interactions) lens of Zepke et al. (2010) Conceptual Organiser. Some of the potential indicators of positive student-teacher interactions are that students will enjoy active and collaborative learning within the classroom. To encourage student engagement teachers must be enthusiastic (Krause \& Coates, 2008; Russell \& Slater, 2011) and well prepared (Mearns et al., 2007 cited in Zepke \& Leach, 2010; Russell \& Slater, 2011). The quantitative data outlined in table 1 emphasises a number of ways that lecturers and their teaching can impact on student engagement. 
Table 1. The importance that students attach to what happens in lectures

\begin{tabular}{lcc}
\hline Question & $\begin{array}{c}\text { \% of students saying that this was } \\
\text { important or very important in the } \\
\text { first cohort }\end{array}$ & $\begin{array}{c}\% \text { of students saying that this was } \\
\text { important or very important in the } \\
\text { second cohort }\end{array}$ \\
$\begin{array}{l}\text { Lecturers teaching in ways that } \\
\text { enable me to learn. }\end{array}$ & 98 & 96 \\
\end{tabular}

Lecturers making the subject really interesting.

Lecturers making content relevant to my goals.

Lecturers having specialist knowledge in their subject.

Lecturers being enthusiastic about their subject.
Our qualitative data in the first phase of data collection also revealed that the quality of lectures would impact on student engagement:

I mean the motivation of why I actually turn up for lectures is because I want to get my degree. But the main thing that de-motivates me is the lecturers themselves. If I've got a boring lecture I don't see the point of me turning up (Female Student, Cohort One).

But the only things that motivates me is what Kay said, like the lecturer 'cause they'll read off the slide and it's like 'I can read it myself'. Then they're like, either they won't expand on it or they'll just read it and just move on. So I'm like well I can just stay at home and read it [off the university VLE] (Female Student, Cohort One).

Students in our second cohort also commented on how the quality of lectures could impact on their experience at university, although in this data the participants tended to focus on how good quality teaching improved their experience and engagement:

Obviously with some of the modules you have to learn through practical but I think that I really enjoyed how they switched it up so that not every day was the same and it wasn't tedious. So tomorrow we come and we are going to be in the pool, whereas today we have been sitting in lectures or seminars (Female Student, Cohort Two).

I always had the vision that university was just lecture, lecture, lecture, lecture and one of the reasons I chose to do PE was that I thought that it might have a bit more of a practical side, which it does, but I wasn't expecting the different variations of teaching like lecture, workshop, seminars, so for me it was a lot better. I have found that I have learnt a lot more than I thought that I would, which is really good (Female Student, Cohort Two)

It is notable that the qualitative data within this theme again highlighted the possibility of an increase in student expectations following the increase in student fees. So, while both cohorts talked about the quality of lectures, only our second group of participants made consistent comment about what they expected in terms of contact time. While many teachers may use timetabled lecture time for a variety of activities, including group activities and tutorial support, for the second cohort of students the expectation was that two hours timetabled lecture time meant precisely that. The following data reflect this theme that only emerged from our second group of students:

One of my expectations of coming to university was that that I thought I would be in here 24/7 like learning, and it hasn't been like that, so I don't feel as though I am in Uni hardly ever and I don't know if that is a good thing or a bad thing because of all the money that I am paying for it and I am only in three times a week for 
three or four hours every day so I don't know what to expect and whether it will go up in the second year and it probably will, but I just thought in the first year I would be in quite a lot learning the experience of university for how much I am paying and I am not (Female Student, Cohort Two).

Yeah, kind of, I expected more, like having more lectures and more contact time with you, like a lecturer, but then again at university you are expected to do your own learning as well, like you are given the basics and then you are expected to find out more, but I did expect like, you know, some of our lectures finish early and if we are paying nine grand a year you kind of expect them to last if it's a two hour lecture, and I know there are a lot of people in lectures that start talking or doing other things, but if you are paying nine grand a year for four lectures a week you kind of expect them to last the whole two hours or whatever they are (Female Student, Cohort Two).

So, while we should again outline that it is beyond the scope of this case study to suggest that an increase in student fees might have caused a change in the nature of student expectations and student engagement, our data certainly highlights such a suggestion as a possible area for future research. Moreover, such data once again suggests that institutions may face a challenge in terms of how they can help staff to meet changing student expectations (Zepke et al., 2010).

\section{Concluding Comments}

This was a study that focussed on two cohorts of students at a single university in the West Midlands region of the UK. Consequently caution should be exercised when making generalisations based on the findings of this study. Nevertheless, we feel that some thought provoking findings around student engagement have emerged. The stated aim of our study was to consider the relevance of Zepke et al. (2010) Conceptual Organiser within the context of Higher Education in the United Kingdom and our data has revealed that many of the factors identified in this Conceptual Organiser were important in encouraging student engagement in our sample of students. Whilst our data suggests the significance of all three psychological need areas identified in Deci and Ryan's SDT (autonomy, competence and relatedness), and while there was some strong references to the importance of institutional support and student-student interaction within our discussion, the most important factor in terms of encouraging students to engage was the way in which their teachers engage with them. Teachers' actions and interactions can be seen to impact all three psychological need areas. This was seen in terms of the quality of relationships that teachers develop with their students, but also in terms of the quality of their teaching. Consequently, this case study would support the comments of Zepke et al. (2010) that when drawing up action plans around student engagement, policy makers should be particularly focussed on the development of teachers and their teaching.

One point of interest to emerge from this case study, however, was that the role of teachers in this area might actually become even more important in the coming years. The timing of our study meant that the data collection with our two different cohorts spanned the introduction of higher student fees for students attending English universities at the start of the 2012/13 academic year and while our data revealed that both sets of students considered staff-student relationships to be very important, the students paying higher fees seemed to expect a lot more from this relationship. Moreover, there were higher expectations in terms of what was expected in terms of lectures and contact time. So, while we have been able to support the view of Zepke et al. (2010) that teachers are the key factor in encouraging student engagement, our study has also hinted that the increase in student tuition fees in England - and the potentially increased expectations that students may have of their teachers as a result - means that teachers may have become even more crucial in encouraging students to engage in their studies.

The initial aims of this paper, coupled with our case study approach, means that it is beyond the scope of this study to come to any definite conclusions about the impact that increased student fees might have on the issues that we have discussed. We would, however, recommend that future research is undertaken to consider these issues in more detail. Our tentative conclusions would suggest that student-teacher interactions may have become an even more important factor in encouraging student engagement. Future research should look to tell us whether teachers and institutions at English universities need to recognise this and whether institutions need to do more to allow staff to meet increased student expectations in order that they may improve student motivation and engagement, thus encouraging greater retention and progression.

\section{References}

Aldcroft, A. (2011). The motivations to study and expectations of studying of undergraduate students in business and management. Journal of Further and Higher Education 35(4), 521-43. http://dx.doi.org/10.1080/0309877X.2011.590581 
Allen, D. (2012). Fees - the impact on the sector. Perspectives: Policy and Practice in Higher Education 16(2), 46-50. http://dx.doi.org/10.1080/13603108.2011.652989

Bryson, C., \& L. Hand. (2007). The role of engagement in inspiring teaching and learning. Innovations in Education and Teaching International 44(4), 349-62. http://dx.doi.org/10.1080/14703290701602748

Busse, V. (2013). Why do first-year students of German lose motivation during their first year at university? Studies in Higher Education 38(7), 951-971. http://dx.doi.org/10.1080/03075079.2011.602667

Byrne, M., \& B. Flood. (2007). Exploring the antecedents of learning approaches: A study of international business students. International Journal of Management Education 6(2), 44-62.

Case, J. (2007). Alienation and engagement: Exploring students' experiences of studying engineering. Teaching in Higher Education 12(1), 119-33. http://dx.doi.org/10.1080/13562510601102354

Case, J. (2008). Alienation and engagement: Development of an alternative theoretical framework for understanding student learning. Higher Education 55: 321-32. http://dx.doi.org/10.1007/s10734-007-9057-5

Clarke, K., \& A. Lane. (2005). Seminar and tutorial sessions: A case study evaluating relationships with academic performance and student satisfaction. Journal of Further and Higher Education 29(1), 15-23. http://dx.doi.org/10.1080/03098770500037689

Coates, H. (2008). Attracting, Engaging and Retaining: New conversations about learning. Australasian Student Engagement Report. Camberwell: Australian Council for Educational Research.

Connell, J. P., \& Wellborn, J. G. (1991). Competence, autonomy, and relatedness: a motivational analysis of self-system processes. In M. R. Gunnar, \& L. A. Sroufe (Eds.). Self processes in development: Minnesota symposium on child psychology, Vol. 23, (pp. 43-77). Chicago: University of Chicago Press.

Deci, E., \& R. Ryan. (1985). Intrinsic motivation and self-determination in human behavior. New York: Plenum Press. http://dx.doi.org/10.1007/978-1-4899-2271-7

Deci, E., \& R. Ryan. (2002). Handbook of self-determination research. Rochester, NY: The University of Rochester Press.

Elliot, A. J., \& Dweck, C. S. (Eds.). (2005). Handbook of competence and motivation. New York: Guilford.

Fazey, D., \& J. Fazey. (2001). The potential for autonomy in learning: Perceptions of competence, motivation and locus of control in first-year undergraduate students. Studies in Higher Education 26(30), 345-61. http://dx.doi.org/10.1080/03075070120076309

Krause, K., \& H. Coates. (2008). Students' engagement in first-year university. Assessment and Evaluation in Higher Education 33(5), 493-505. http://dx.doi.org/10.1080/02602930701698892

Leach, L., \& N. Zepke. (2011). Engaging students in learning: A review of a conceptual organiser. Higher Education Research and Development 30(2), 193-204. http://dx.doi.org/10.1080/07294360.2010.509761

Llorens, S., W. Schaufeli, A. Bakker, \& M. Salanova. (2007). Does a positive gain spiral of resources, efficacy beliefs and engagement exist? Computers in Human Behaviour 23, 825-41. http://dx.doi.org/10.1016/j.chb.2004.11.012

Mann, S. (2001). Alternative perspectives on the student experience: Alienation and engagement. Studies in Higher Education 26(1), 7-19. http://dx.doi.org/10.1080/03075070020030689

Moran, E., \& T. Gonyea. (2003). The influence of academically-focused peer interaction on college students' development. ERIC Document Reproduction Service No. ED478773.

Patton, M. (2002) Qualitative Research \& Evaluation Methods. Sage: London.

Reason, R., P. Terenzini, \& R. Domingo. (2006). First things first: Developing academic competence in the first year of college. Research in Higher Education 47(2), 149-75. http://dx.doi.org/10.1007/s11162-005-8884-4

Regalado, M. (2003). Competence, confidence, and connections. College \& Undergraduate Libraries 10(2), 89-97. http://dx.doi.org/10.1300/J106v10n02_08

Roberts, S. (2011). Traditional practice for non-traditional students? Examining the role of pedagogy in Higher Education retention. Journal of Further and Higher Education 35(2), 183-99. http://dx.doi.org/10.1080/0309877X.2010.540320

Russell, B., \& G. Slater. (2011). Factors that encourage student engagement: Insights from a case study of 'first time' students in a New Zealand University. Journal of University Teaching and Learning Practice 8(1) article 7. 
Silverman, D. (2006). Interpreting qualitative data. Sage: Padstow.

Strauss, A. \& Corbin, J. (1998). Basics of qualitative research. Sage: London.

Umbach, P., \& M. Wawrzynski. (2005). Faculty do matter: The role of college faculty in student learning and engagement. Research in Higher Education 46(2), 153-84. http://dx.doi.org/10.1007/s11162-004-1598-1

Wang, M. \& Eccles, J.S. (2013). School context, achievement motivation, and academic engagement: A longitudinal study of school engagement using a multidimensional perspective. Learning and Instruction 28, 12-23. http://dx.doi.org/10.1016/j.learninstruc.2013.04.002

Xuereb, S. (2013). Academic resourcefulness, coping strategies and doubting in university undergraduates. Journal of Further and Higher Education. http://dx.doi.org/10.1080/0309877X.2013.817004

Yorke, M., \& P. Knight. (2004). Self-theories: Some implications for teaching and learning in higher education. Studies in Higher Education 29(1), 25-37. http://dx.doi.org/10.1080/1234567032000164859

Zepke, N., P. Butler, \& L. Leach. (2012). Institutional research and improving the quality of student engagement. Quality in Higher Education 18(3), 329-47. http://dx.doi.org/10.1080/13538322.2012.730338

Zepke, N., \& L. Leach. (2010). Improving student engagement: Ten proposals for action. Active Learning in Higher Education 11(3), 167-77. http://dx.doi.org/10.1177/1469787410379680

Zepke, N., L. Leach, \& P. Butler. (2010). Student engagement: What is it and what influences it? Wellington, Teaching and Learning Research Initiative. http://www.tlri.org.nz/sites/default/files/projects/9261-Introduction.pdf

Zepke, N., L. Leach, and P. Butler. (2011). Non-institutional influences and student perceptions of success. Studies in Higher Education 36(2), 227-42. http://dx.doi.org/10.1080/03075070903545074

\section{Notes}

Note 1. Zepke, Leach, and Butler, (2010) used the term teacher to describe those teaching in HE. In the UK the term lecturer is also used to describe this role. In the current study both terms are used at various points - within our discussion and our data - in order to describe this role. 